\title{
Reparação do tecido osteocondral da crista sagital do osso metacarpiano principal em um equino - relato de caso
}

Luis Cláudio Lopes Correia da Silva ${ }^{[a]}$, Rodrigo Tavares Nieman ${ }^{[a]}$, Fernanda Manzano de Campos[ ${ }^{[b]}$, Cynthia do Prado Vendrusculo[a], Rose Eli Grassi Rici[a], Aura Chaves Rosauro ${ }^{\left[{ }^{[a]}\right.}$, Carolina Brandão Serrano ${ }^{[a]}$, Raquel Yvonne Arantes Baccarin ${ }^{[a]}$

\author{
[a] Faculdade de Medicina Veterinária e Zootecnia, Universidade de São Paulo (USP), São Paulo, SP, Brasil \\ ${ }^{[b]}$ Equine Center, São Paulo, SP, Brasil \\ [c] Médica veterinária, São Paulo, SP, Brasil
}

*Autor correspondente

e-mail: rodrigo_nieman@hotmail.com

\section{Resumo}

Doenças osteocondrais e osteoartrite são caracterizadas pela degradação focal ou difusa da cartilagem articular e consequente prejuízo da função articular. As estratégias atuais de tratamento, conservativas e cirúrgicas, não resultam em restauração total da cartilagem hialina e, portanto, trazem um prognóstico reservado. A profundidade da lesão, o tamanho, localização em relação à carga de apoio e idade do animal influenciam a taxa de reparo e a resiliência da nova superfície de tecido fibrocartilagíneo. 0 diagnóstico das afecções articulares se baseia comumente no exame físico e radiográfico, tendo como achados comuns aqueles relacionados às alterações do tecido ósseo, particularmente o osso subcondral e o colapso articular. A extensão da degradação articular é melhor avaliada por artroscopia, porém, exames diagnósticos avançados, como a ressonância magnética, podem ser utilizados, além da avaliação histológica do tecido. Uma potra Mangalarga, de 1 ano e 8 meses de idade, foi submetida à artroscopia metacarpofalangeana esquerda para tratamento de cisto subcondral em região dorsodistal da crista sagital. Após 10 meses, o animal não apresentava claudicação ou outra alteração perceptível ao exame físico da articulação operada, mas teve óbito em decorrência de quadro de abdômen agudo. Através das devidas técnicas de necropsia, o membro torácico esquerdo foi removido do esqueleto do animal e seccionado proximalmente à articulação radiocárpica, e o tecido osteocondral cicatrizado da crista sagital do terceiro metacarpiano foi, então, analisado por radiografia, ultrassonografia, ressonância magnética e artroscopia, além da avaliação macroscópica e histológica da lesão tratada. As imagens radiográficas evidenciaram bom preenchimento da lesão cística anteriormente curetada. 0 exame ultrassonográfico mostrou, principalmente, achatamento da crista sagital associada à irregularidade do osso subcondral adjacente. A ressonância magnética identificou 
presença de área erosiva côncava uniforme no local da lesão. Durante o procedimento artroscópico, pôde-se evidenciar formação de fibrocartilagem revestindo a superfície articular da crista sagital do metacarpiano principal e a avaliação macroscópica global do reparo obteve escore 9 (grau 2 ou quase normal) segundo o ICRS (International Cartilage Repair Society). A histologia confirmou presença de matriz colágena com característica de fibrocartilagem, além da presença de condrócitos. Os resultados indicam que a associação dos métodos de diagnóstico por imagem é fundamental não apenas no diagnóstico de lesões osteocondrais, mas também no acompanhamento pós-operatório do processo cicatricial. A análise histológica comprovou que o tecido de reparação neoformado foi composto de fibrocartilagem de boa qualidade. A avaliação geral do reparo da lesão cística curetada, neste caso, demonstrou a eficiência do tratamento no período de 10 meses e a relação positiva entre exame de imagem e análise macroscópica e histológica da cicatrização osteocondral.

Palavras-chave: Articulação metacarpofalangeana. Tecido osteocondral. Diagnóstico por imagem. 